Research, Society and Development, v. 9, n. 10, e709108412, 2020

(CC BY 4.0) | ISSN 2525-3409 | DOI: http://dx.doi.org/10.33448/rsd-v9i10.8412

\title{
Estilos de aprendizagem e desempenho em curso técnico em edificações
}

Learning styles and performance in building technical course

Estilos de aprendizaje y desempeño en curso técnico en edificación

Recebido: 13/09/2020 | Revisado: 14/09/2020 | Aceito: 16/09/2020 | Publicado: 19/09/2020

\section{Ramon Paes Guimarães}

ORCID: https://orcid.org/0000-0002-5784-2570

Instituto Federal de Educação, Ciência e Tecnologia de Minas Gerais, Brasil

E-mail: ramon.guimaraes@ifmg.edu.br

Wanderson Gonçalves Machado

ORCID: https://orcid.org/0000-0002-5923-9425

Instituto Federal de Educação, Ciência e Tecnologia de Minas Gerais, Brasil

E-mail: wanderson.machado@ifmg.edu.br

Reginaldo Gonçalves Leão Junior

ORCID: https://orcid.org/0000-0002-3596-2256

Instituto Federal de Educação, Ciência e Tecnologia de Minas Gerais, Brasil

E-mail: reginaldo.junior@ifmg.edu.br

\section{Resumo}

Os estudantes da Rede Federal de Educação Profissional, Científica e Tecnológica, mesmo geralmente ingressando após processos seletivos concorridos, também enfrentam dificuldades para manterem um bom desempenho. Estudos no campo, com destaque aos de Felder e Silverman, apontam que parte significativa disso se relaciona diretamente com os estilos de aprendizagem, que são padrões comportamentais individuais que podem implicar em maior ou menor facilidade para aprender determinado assunto. $\mathrm{O}$ presente estudo apresenta os resultados de uma investigação que buscou identificar influências de estilos de aprendizagem de professor e estudantes sobre o desempenho escolar, levando-se em consideração também os métodos didáticos utilizados. O contexto analisado foi o do Curso Técnico Integrado em Edificações do IFMG Campus Santa Luzia, especificamente nas disciplinas de Estabilidade das Construções e Matemática. A metodologia consistiu fundamentalmente na aplicação de questionário adaptado ao contexto brasileiro para caracterização dos estilos a estudantes e professores. Dentre os resultados, destaca-se que os melhores desempenhos estiveram mais 
ligados a estilos mais flexíveis dos estudantes do que a uma convergência em relação ao estilo do professor.

Palavras-chave: Estilos de aprendizagem; Desempenho; Evasão; Técnico em edificações.

\begin{abstract}
Students of the Federal Network of Professional, Scientific and Technological Education, even though they usually enter after successful selection processes, they also face difficulties to maintain a good performance. Studies in the field, especially those by Felder and Silverman, point out that a significant part of this situation is directly related to learning styles, which are individual behavioral patterns that may imply greater or lesser ease to learn certain subjects. This study presents the results of an investigation that sought to identify the influences of teacher and student learning styles on school performance, taking also into account the didactic methods used. The context analyzed was that of the Integrated Building Technical Course at the IFMG Campus Santa Luzia, specifically in the disciplines of Construction Stability and Mathematics. The methodology consisted fundamentally in the application of a questionnaire adapted to the Brazilian context to characterize the students and teachers' styles. Among the results, it is emphasized that the best performances were more linked to more flexible styles of students than to a convergence in relation to the teacher's style.
\end{abstract}

Keywords: Learning styles; Performance; Evasion; Building technical course.

\title{
Resumen
}

Los estudiantes de la Red Federal de Educación Profesional, Científica y Tecnológica, aunque suelen ingresar luego de procesos competitivos de selección, también enfrentan dificultades para mantener un buen desempeño. Los estudios de campo, especialmente los de Felder y Silverman, señalan que una parte significativa de esto está directamente relacionada con los estilos de aprendizaje, que son patrones de comportamiento individuales que pueden implicar mayor o menor facilidad para aprender una determinada materia. Este estudio presenta los resultados de una investigación que buscó identificar las influencias de los estilos de aprendizaje de docentes y alumnos en el desempeño escolar, teniendo en cuenta también los métodos didácticos utilizados. El contexto analizado fue el del Curso Técnico Integrado en Edificación en el IFMG Campus Santa Luzia, específicamente en las disciplinas de Estabilidad de la Construcción y Matemáticas. La metodología consistió fundamentalmente en la aplicación de un cuestionario adaptado al contexto brasileño para caracterizar los estilos 
a estudiantes y profesores. Entre los resultados, destaca que los mejores desempeños estuvieron más vinculados a estilos de estudiantes más flexibles que a una convergencia en relación al estilo del docente.

Palabras clave: Estilos de aprendizaje; Actuación; Evasión; Técnico en edificaciones.

\section{Introdução}

A Rede Federal de Educação Profissional, Científica e Tecnológica teve início no Brasil em 1909 e atualmente são mais de 600 campi. Fazem parte da rede os IF's - Institutos Federais de Educação, Ciência e Tecnologia, CEFET's - Centros Federais de Educação Tecnológica, Escolas Técnicas Vinculadas às Universidades Federais, Universidade Tecnológica Federal do Paraná e Colégio Pedro II (Brasil, 2016). Em todos existem cursos técnicos, ensino médio integrado e cursos superiores e, em vários, também de pós-graduação.

De acordo com lei que institui a Rede Federal, metade das vagas devem atender à "educação profissional técnica de nível médio, prioritariamente na forma de cursos integrados, para os concluintes do ensino fundamental e para o público da educação de jovens e adultos" (Brasil, 2008). Assim, a discussão aqui se concentra sobre os cursos técnicos integrados. Com processos seletivos significativamente concorridos, os estudantes desses cursos tendem a pertencer ao grupo dos de maior desempenho no contexto local. Mesmo assim, eles também encontram dificuldades no decorrer dos cursos.

Segundo Piazzi (2014), parte importante do baixo desempenho dos estudantes se relaciona à maneira que estudam. A prática recorrente de estudar apenas nas vésperas das provas desempenha um papel apenas na memória de curto de prazo, fazendo com que o conhecimento não se consolide de fato. Para Piazzi, seria necessário recriar hábitos, o que, em uma abordagem mais ampla, corresponde a recriar habitus ${ }^{l}$, envolvendo questões como contexto familiar, costumes, valores sociais, etc.

Paralelamente, conhecimentos falsamente aprendidos são diversas vezes consolidados nos registros escolares como se tivessem sido de fato aprendidos. Trata-se das distorções de avaliação de aprendizagem, discutidas por Luckesi (2014). Por exemplo, na típica distribuição de pontos. Marcar 2 pontos em 10 sobre a Primeira Lei de Newton e 10 pontos em 10 sobre a Terceira Lei de Newton é somado como 12 em 20, ou 60\%. Embora o registro indique que o

\footnotetext{
${ }^{1}$ O termo habitus é utilizado aqui conforme a abordagem de Pierre Bourdieu, de sistema das disposições socialmente constituídas que, enquanto estruturas estruturantes, constituem o princípio gerador e unificador do conjunto das práticas e das ideologias características de um grupo de agentes (Bourdieu, 2005).
} 
desempenho foi de $60 \%$ em Leis de Newton, a distorção é notória, já que são dois assuntos, ou qualidades, distintas.

Existem outras distorções recorrentes, como na elaboração das avaliações, na determinação dos critérios e do que vale ponto ou não, a sobreposição da importância dos pontos sobre o aprendizado etc. Tudo isso favorece ao problema de criação de lacunas de aprendizado mês a mês, ano a ano, que em determinados momentos se tornam evidentes, como nos cursos técnicos. Os históricos de registros de aprovação no ensino fundamental e, inclusive o do processo seletivo, pressupõe, em tese, que o estudante detém os conhecimentos mínimos necessários. Porém, dificilmente um professor atento a essas questões poderia concordar com isso.

Outra dificuldade encontrada pelos estudantes diz respeito à má gestão e administração do tempo. Essa questão também é tratada por Piazzi (2014), no sentido de que é necessário haver uma certa obediência e disciplina para estudar, até que isso se torne um hábito. E estudar de maneira ativa, realizando atividades e problemas, ao contrário da postura passiva de apenas assistir a aula. Contudo, pode existir também uma incompatibilidade entre tempo e prazo oriunda da própria instituição de ensino. No caso de cursos técnicos integrados ao ensino médio, cargas horárias em sala de aula elevadas combinadas a atividades extraclasse que exigem muito tempo de dedicação, podem ter consequências, além do baixo desempenho em avaliações, em problemas psicológicos aos estudantes ${ }^{2}$.

Se em tempos anteriores à Revolução Industrial o ensino dos ofícios se pautava sobretudo nas relações de mestre e aprendiz, com acompanhamento próximo do aprendizado, o modelo de ensino vigente até então consiste em salas de aula com muitos estudantes e apenas um professor, que dificilmente é capaz de acompanhar de perto o desenvolvimento de cada estudante (com algumas exceções de turmas divididas, por exemplo em aulas em laboratórios). Alguns estudantes, seja por afinidade ao assunto, conhecimentos prévios, motivação intrínseca ou empatia ao professor, aprendem melhor que outros. Na realidade, isso se relaciona diretamente com os estilos de aprendizagem, que são padrões comportamentais individuais que podem implicar em maior ou menor facilidade para aprender determinado assunto. Mais do que isso, estudos como os de Felder \& Silverman (1988) apontam que a afinidade de estilos do estudante e do professor (sendo o estilo de ensinar um reflexo direto do próprio estilo de aprendizagem) podem ser determinantes para o aprendizado do estudante,

\footnotetext{
${ }^{2}$ Karklins \& Mendoza (2016) e diversas outras pesquisas em vários países apontam para índices significativos de estresse e tratamentos psicológicos por estudantes devido a excessivas cargas horárias e nível de cobrança.
} 
com reflexos em níveis de atenção, motivação e aprendizado efetivo.

A partir desse contexto, o presente estudo apresenta os resultados de uma investigação que buscou identificar influências de estilos de aprendizagem de professor e estudantes, levando-se em consideração também os métodos didáticos utilizados. Como estudo de caso, o contexto analisado foi o do Curso Técnico Integrado em Edificações, especificamente nas disciplinas de Estabilidade das Construções e Matemática, que se caracterizam por serem disciplinas com ênfase em cálculos e que apresentam recorrentemente maiores índices de reprovação, sendo uma disciplina do eixo da formação profissional e outra do ensino médio.

A expressão estilos de aprendizagem é utilizada para se referir a uma série de teorias que visam explicar diferenças na aprendizagem dos indivíduos (Coffield et al., 2004). Coffield et al. (2004) levantam a existência de diversos métodos nos campos da psicologia, sociologia, educação, neurobiologia, dentre outras. Dentre todos, o de Felder e Silverman (1988) merece destaque no contexto brasileiro, já que, além de ser um dos mais difundidos na literatura (Vieira Junior, 2014), também teve uma versão adaptada ao idioma português por Vieira Junior $(2014)^{3}$. Diante disso, esse foi o modelo utilizado no presente estudo para a identificação dos estilos de aprendizado e será melhor descrito adiante.

A hipótese aqui tratada é de que a incompatibilidade de estilos de aprendizado de professor e estudantes seja um importante fator para o baixo desempenho e as reprovações, o que se caracteriza, como um importante problema, uma vez que isso pode estar intimamente ligada à evasão escolar, ressaltando sua relevância. Embora reconheça-se que existem diversas outras questões envolvidas e com diferentes níveis de influência sobre o aprendizado e o desempenho, é conjecturado que os estilos de aprendizagem também se relacionam aos nível de motivação que, em última instância, impactam sobre o problema da evasão escolar ou, pelo menos, na evasão do campo do conhecimento ${ }^{4}$.

Além de demonstrar a convergência ou não do estudo de caso em relação à hipótese apresentada, é esperado que os resultados sejam utilizados como importantes subsídios para aprimoramentos didáticos não apenas para o curso analisado, mas para quaisquer disciplinas

\footnotetext{
3 Ressalta-se que, dentre os 58 métodos levantados por Coffield et al. (2004), nenhum foi elaborado originalmente em língua portuguesa.

${ }^{4}$ Não é defendido aqui que o estudante deva obrigatoriamente trabalhar com o curso ou seguir seus estudos na mesma área. Contudo, defende-se aqui a ideia de retorno direto, pelo menos de maneira predominante, de recursos financeiros e humanos na formação de profissionais técnicos, a essência desse tipo de formação. Isso também converge a uma das finalidades da Rede Federal, que é de "promover a integração e a verticalização da educação básica à educação profissional e educação superior” (Brasil, 2008).
} 
semelhantes.

\subsection{Referencial Teórico}

Os estilos de aprendizagem são aqui tratados conforme os estudos de Felder \& Silverman (1988), que podem ser compreendidos como uma maneira padrão comportamental pela qual a pessoa possui maior facilidade para aprender. Vieira Junior (2014) levanta que o modelo de Felder e Silverman é um dos mais difundidos na literatura é composto por quatro dimensões:

- $\quad$ Percepção (sensorial ou intuitiva);

- $\quad$ Entrada (visual ou verbal);

- $\quad$ Processamento (ativo ou reflexivo);

- $\quad$ Entendimento (sequencial ou global).

Cada estudante tende a um dos polos de cada dimensão, fazendo com que existam 16 estilos de aprendizagem. Segundo esse modelo, os estilos de ensino são reflexos do próprio estilo de aprendizagem. Em resumo, enquanto sensoriais gostam de fatos, dados e experimentação e preferem observar os fenômenos pelos sentidos - vendo, tocando e ouvindo, intuitivos gostam de conceitos e teorias e preferem analisar fenômenos teoricamente por princípios e modelos. Enquanto visuais se lembram melhor daquilo que veem - imagens, diagramas, filmes e demonstrações, verbais têm boa argumentação e preferem uma explicação verbal a uma demonstração visual. Ativos trabalham bem em grupo e tendem a ser experimentalistas, gostando de fazer as coisas por si próprios e reflexivos não aprendem muito em situações onde não são levados a pensar sobre algo, tendendo a serem bastante teóricos. Sequenciais possuem raciocínio linear durante a solução de questões e se dão bem com problemas que progressivamente se tornam mais complexos, entendendo geralmente primeiro as pequenas partes para depois compreender o todo. Globais, por fim, raciocinam por saltos intuitivos e nem sempre são capazes de explicar como chegaram à solução, normalmente entendendo primeiro o todo e depois compreendendo as pequenas partes (Vieira Junior, 2018).

Felder \& Silverman (1988) argumentam que a incompatibilidade entre os estilos de estudantes e professores pode tornar os estudantes entediados, desatentos e desanimados em relação a aula, com reflexos diretos sobre a aprendizagem. Para determinar os estilos de 
aprendizagem, o modelo apresenta um questionário de 44 perguntas e um método de compilação das respostas que, ao final, fornece o estilo de aprendizagem - ou ensino - do respondente (Felder \& Solomon, 2018). Vieira Junior (2014), verificando divergências nos resultados da aplicação do questionário para estudantes brasileiros (visto que o questionário original é em língua inglesa), propõe o Novo Índice de Estilos de Aprendizagem (N-ILS), composto por 20 perguntas, e o valida matematicamente.

Como tentativas de explicar as dificuldades dos estudantes, algumas pesquisas vêm sendo desenvolvidas nos últimos anos. Serão destacadas aqui as realizadas no âmbito da educação profissional e tecnológica de nível médio. Por exemplo, Figueiredo et al. (2008) aplicam o modelo de Felder \& Silverman (1988) em estudantes e professores dos cursos Técnicos em Agropecuária de Escolas Técnicas Federais do Estado de Goiás, cujos resultados apontam para a necessidade de os estudantes desenvolverem habilidades pertencentes a cada uma das dimensões, consistindo uma preocupação de que "se a eles não for dada a oportunidade de usar seus estilos menos preferidos, eles poderão ter dificuldade em desenvolver as habilidades ligadas a essas categorias" (Figueiredo et al., 2008).

Catholico \& Oliveira Neto (2009) avaliam diferentes estilos de aprendizagem em um grupo de estudantes que, ao concluírem o ensino médio, optaram por fazerem um curso técnico de eletroeletrônica ao invés de procurarem o ensino superior. O estudo verifica que os estilos predominantes são visuais, reflexivos, ativos e sequenciais, considerado um comportamento notavelmente direcionado para aulas práticas, convergindo com suas decisões em cursarem esse tipo de curso, ao invés de cursos superiores.

Já o estudo de Amaral \& Silveira (2014) mapeia os estilos de aprendizagem dos estudantes do $3^{\circ}$ ano do curso técnico em informática de formação integrada do CEFET-MG, levantando perfis cognitivos dominantes. O estudo constata que os estudantes possuem perfis de aprendizagem condizentes com as premissas do Projeto Pedagógico do Curso, o que é considerado benéfico para o aprendizado.

Os estudos sobre estilos de aprendizagem também apontam para influências e tendências ligadas a gênero. Por exemplo, Leitão (2006) investiga estilos de aprendizagem sob a ótica da Psicologia Evolucionista, com o objetivo de investigar esses estilos em adolescentes e suas correlações com os interesses escolares e profissionais, assim como tais variáveis em função do gênero em diversas escolas públicas e privadas de Natal - $\mathrm{RN}^{5}$. O

\footnotetext{
${ }^{5}$ Os estudos de Leitão (2006) não se baseiam no modelo Felder e Silverman, como a maioria dos estudos desse tipo, mas sim nos Estilos de Aprendizagem Experiencial de David Kolb, que propõe quatro diferentes estilos: "divergente, caracterizado pela orientação para pessoas e visão por distintas perspectivas; assimilador, ligado a
} 
estudo aponta que, enquanto adolescentes do sexo feminino tendem mais a disciplinas de línguas e atividades com pessoas, os do sexo masculino preferem disciplinas exatas e atividades técnicas, o que ficou evidenciado no número de inscritos do sexo masculino em áreas exatas e engenharias e do sexo feminino em ciências humanas e sociais. Com foco semelhante, Honigsfeld \& Dunn (2010) estudam semelhanças e diferenças no estilo de aprendizagem masculino e feminino do ensino médio em 5 países: Bermuda, Brunei, Hungria, Suécia e Nova Zelândia. Os autores sustentam que os padrões de diferenças de gênero nos estilos de aprendizagem são observáveis e incentivam os educadores a considerar os pontos fortes de todos os estudantes para maximizar os resultados instrucionais.

Ainda nesse mesmo viés, Mathews \& Hamby (2010) comparam os estilos de aprendizagem de estudantes do ensino médio e universitários no Sudeste dos Estados Unidos. Com análises além às de gênero, a pesquisa aponta que existem diferenças significativas nos estilos de aprendizagem entre os grupos, como raça (entendido aqui como grupo étnico) e gênero como fatores que influenciam os estilos de aprendizagem.

Alguns estudos sobre estilos de aprendizagem se voltam diretamente para a influência em taxas de reprovação. Trevelin (2007), por exemplo, investiga estilos de estudantes e professores dos cursos de Tecnologia de Produção Industrial e Tecnologia em Processamento de Dados de uma Faculdade em Taquaritinga-SP, utilizando os inventários de Felder e Soloman e o de Keirsey e Bates. Após traçados os perfis dos estilos de aprendizagem dominantes dos estudantes e professores, correlacionados com os dados do Sistema de Avaliação Institucional, o SAI, da própria faculdade, a pesquisa aponta a existência de interferências nas relações de ensino-aprendizagem e ligações com os altos índices de reprovação em determinadas disciplinas.

No contexto brasileiro, as dificuldades de aprendizado se refletem diretamente em índices de reprovação, com destaque para algumas disciplinas. Segundo dados do INEP do ano de 2003, dos estudantes brasileiros da $3^{\text {a }}$ série do ensino médio, na disciplina de Matemática, $62,6 \%$ foram classificados no estágio crítico e outros $4,8 \%$ no estágio muito crítico do aprendizado (INEP, 2003).

Costa Junior et al. (2017) analisam a correlação entre as notas dos estudantes em Física e nas demais disciplinas de interesse, visto que grande parte dos estudantes de ensino médio enfrentam sérias dificuldades em Física, o que pode ser observado pelos elevados 
índices de repetência associados a essa disciplina. Os resultados mostram que os maiores valores de correlação são encontrados entre as notas de Matemática e Física e entre a média das notas de Química e Biologia e as notas em Física, apontando para um trabalho interdisciplinar e integrado entre disciplinas de um mesmo eixo do conhecimento.

Dantas Filho (2018), por meio da aplicação de um questionário aos estudantes do curso de Engenharia de Pesca da Universidade Federal de Roraima, relata um baixo rendimento em Matemática. As informações sugerem acúmulos de deficiências ao longo da trajetória escolar, com constantes alegações de desinteresse e, até mesmo, insegurança e repúdio ao assunto. Sendo que grande parte dos acadêmicos admitiram que não estavam aptos para o ENEM (Exame Nacional do Ensino Médio) porque não haviam definido suas profissões.

Almeida Junior et al. (2018) investigam possíveis causas de baixo desempenho nas disciplinas de Física em Engenharias. A pesquisa aponta que grande parte do índice de reprovações nos cursos de engenharias pode estar associada à deficiência no conhecimento de matemática básica.

Moreira (2000) destaca que, em Física, o estudante deve, ao final da disciplina, compreender enunciados dos problemas estudados (nota-se que a disciplina de Português também é de extrema importância para o aprendizado de Física no caso deste artigo, mas que se estende para a Matemática e também às demais disciplinas), para então ter a capacidade de calcular, dimensionar bem como avaliar a ordem de grandeza dos parâmetros mensurados.

Nos anos 1990, o Ministério da Educação (MEC) por intermédio do Instituto Nacional de Estudos e Pesquisas Educacionais Anísio Teixeira (INEP), criou um instrumento de avaliação, o Sistema de Avaliação da Educação Básica (SAEB). Um dos objetivos principais do SAEB é coletar informações e apresentar aos gestores públicos e educacionais e a toda a sociedade, para que tenham uma visão mais abrangente em termos de qualidade da educação básica brasileira (SAEB, 2017).

Os dados do SAEB (2017) apontam que, pela primeira vez, o MEC classificou os níveis de proficiência, organizados em uma escala de 0 a 9. Níveis de 0 a 3 são considerados insuficientes; entre 4 e 6 os estudantes têm nível de conhecimento básico; e de 7 até 9, adequado. Conforme dados Relatório do SAEB (2017), o ensino médio foi classificado no nível 2 de proficiência, como mostrado na Figura 1. Em Matemática, 71,67\% dos estudantes têm nível insuficiente de aprendizado. Desses, 23\% estão no nível 0. Em Português a situação é semelhante: 70,88\% dos estudantes têm nível insuficiente de aprendizado, sendo que 23,9\% estão no nível zero, ou seja, aproximadamente sete de cada dez estudantes do $3^{\circ}$ ano do ensino 
médio tem nível insuficiente em Português e Matemática (SAEB, 2017).

Figura 1. Dados do Saeb 2017 mostram médias de proficiência em Português e Matemática.

$3^{\circ}$ ANO
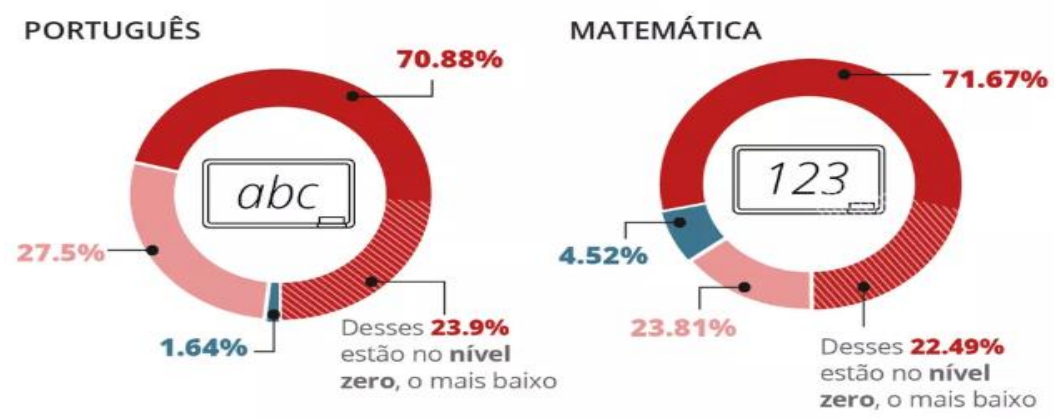

Fonte: Inep/ MEC

Fonte: G1 (2018).

Sato e Ramos (2014) afirma que os altos índices de repetência e evasão nos cursos técnico e superior estão ligados às disciplinas relacionadas ao domínio dos conceitos de matemática, física, química e biologia. De maneira semelhante, baixos índices também são verificados na formação de técnicos, tecnólogos e engenheiros (para os técnicos em edificações e engenheiros a física e a matemática estão ainda mais ligadas devido a serem amplamente abordadas).

Santos et al. (2020) realizaram um estudo com o intuito de traçar o perfil do estudante evadido do curso Técnico em Edificações Subsequente do IFMG - Campus Piumhi. Os autores citam, entre outras questões, que o crescimento da oferta de monitoria aos estudantes seria importante para que não ocorresse a evasão, uma vez que se o estudante tiver concluído o ensino médio em um tempo expressivo, pode ser que tenha uma maior dificuldade nas disciplinas do curso.

\section{Metodologia}

A pesquisa foi dividida em duas partes fundamentais: lançamento de questionário e análise das respostas. Primeiramente, o questionário de 20 perguntas de Vieira Junior (2014) foi transcrito para um formulário eletrônico e enviado para o e-mail de todos os estudantes que cursaram em 2019 o segundo ano do Curso Técnico Integrado em Edificações do IFMG campus Santa Luzia, abrangendo todos os que cursaram simultaneamente Estabilidade das 
Construções e Matemática. Paralelamente, o formulário foi enviado aos professores das duas disciplinas, que também registraram os principais métodos didáticos e de avaliação utilizados, além do registro final de notas.

O formulário com o questionário foi formatado para possibilitar apenas as respostas "a" e "b", exatamente como estabelecido por Vieira Junior (2014), permitindo que fosse respondido em cerca de dois a três minutos. As respostas do questionário e as notas foram lançadas em uma planilha eletrônica para a compilação dos dados. Uma vez com esses dados na planilha, teve início a organização das informações. Os estudantes foram divididos em dois grupos com a mesma quantidade de estudantes: os 50\% com as melhores notas e os $50 \%$ com as menores nota, entendidos aqui respectivamente como "aprendizagem baixa" e "aprendizagem alta"6. Os estilos de aprendizagem predominantes de cada um desses grupos foram confrontados com os dos professores. Nesse sentido, a metodologia utilizada pode ser considerada como qualitativa transformada em quantitativa, como tratado por Pereira et al. (2018). Isto é, as respostas ao questionário, fundamentalmente qualitativas, foram sintetizadas em respostas comuns (as opções e os indicadores "a" e "b") e, em seguida, foram calculados os percentuais para cada resposta e em cada grupo de estudantes.

Por fim, os dados também foram confrontados com os registros das principais metodologias didáticas. Nessa análise, também conforme o exposto por Pereira et al. (2018), a metodologia utilizada é fundamentalmente qualitativa, principalmente por utilizar dados descritivos, isto é, os relatos dos professores. Sendo assim, a metodologia utilizada na pesquisa é uma mescla entre quantitativa e qualitativa.

\section{Resultados e Discussão}

O questionário foi respondido em agosto de 2020 por 32 dos 74 estudantes que finalizaram as disciplinas (43\%). Em Matemática, a divisão entre os dois grupos foi a nota 75 e em Estabilidade das Construções foi 69, diferença entendida aqui como resultado da diferença de critérios de avaliação, pesos e nível de rigor de cada um dos professores. As notas médias das disciplinas foram respectivamente 75 (igual à nota de divisão) e 70 (quase igual), reforçando o entendimento exposto.

$\mathrm{O}$ estilo predominante entre os estudantes com menor aprendizagem em Matemática

\footnotetext{
6 Sabe-se que as notas podem não refletir diretamente a aprendizagem. Contudo, esta pesquisa parte do pressuposto de que os métodos avaliativos e as respectivas notas resultantes refletem a aprendizagem com precisão/aproximação satisfatória.
} 
está na (Tabela 1). Cada linha representa uma dimensão. A proximidade dos pólos (5a e 5b) indica muita ênfase e proximidade dos centros (1a e 1b) indica situações equilibradas e maior facilidade para lidar com diferentes contextos. A intensidade da cor representa graficamente o percentual de estudantes em cada uma das quatro dimensões e indicação em amarelo com a marcação (*) representa o estilo do professor de Matemática. O estilo predominante dos estudantes nesse grupo, então, é o: reflexivo (1b) / sensorial (5a) / visual (3a) / sequencial (5a). E o do professor é o: reflexivo (1b) / sensorial (5a) / visual (3a) / sequencial (5a). Notase que existe uma tendência aos extremos vinculados ao lado "a", exceto na primeira dimensão, que o estilo da maior parte dos estudantes e o professor é centralizada nas posições $1 \mathrm{a}$ e $1 \mathrm{~b}$.

Tabela 1. Estilos de aprendizagem dos estudantes com as menores notas em Matemática.

\begin{tabular}{|c|c|c|c|c|c|c|c|}
\hline & $5 a$ & $3 a$ & $1 \mathrm{a}$ & $1 b$ & $3 b$ & $5 b$ & \\
\hline Ativo & $19 \%$ & $13 \%$ & $25 \%$ & $31 \% *$ & $13 \%$ & $0 \%$ & Reflexivo \\
\hline Sensorial & $38 \% *$ & $19 \%$ & $13 \%$ & $13 \%$ & $19 \%$ & $0 \%$ & Intuitivo \\
\hline Visual & $25 \%$ & $38 \% *$ & $13 \%$ & $13 \%$ & $6 \%$ & $6 \%$ & Verbal \\
\hline Sequencial & $31 \% *$ & $19 \%$ & $13 \%$ & $25 \%$ & $13 \%$ & $0 \%$ & Global \\
\hline
\end{tabular}

(*) Estilo do Professor de Matemática. Fonte: Próprios autores.

Da mesma maneira, foi feita a análise dos estudantes com maior aprendizagem em Matemática (Tabela 2). O estilo predominante nesse grupo é o: ativo (3a) / sensorial (3a) / visual (5a) / sequencial (3a). E o do professor é o: reflexivo (1b) / sensorial (5a) / visual (3a) / sequencial (5a). Nesse caso, a maior parte dos estudantes possui uma tendência voltada ao lado "a" em todas as quatro dimensões. Nota-se também que em nenhuma das quatro dimensões a predominância principal (maior percentual) corresponde ao dos estudantes com as menores notas (Tabela 1). 
Tabela 2. Estilos de aprendizagem dos estudantes com as maiores notas em Matemática.

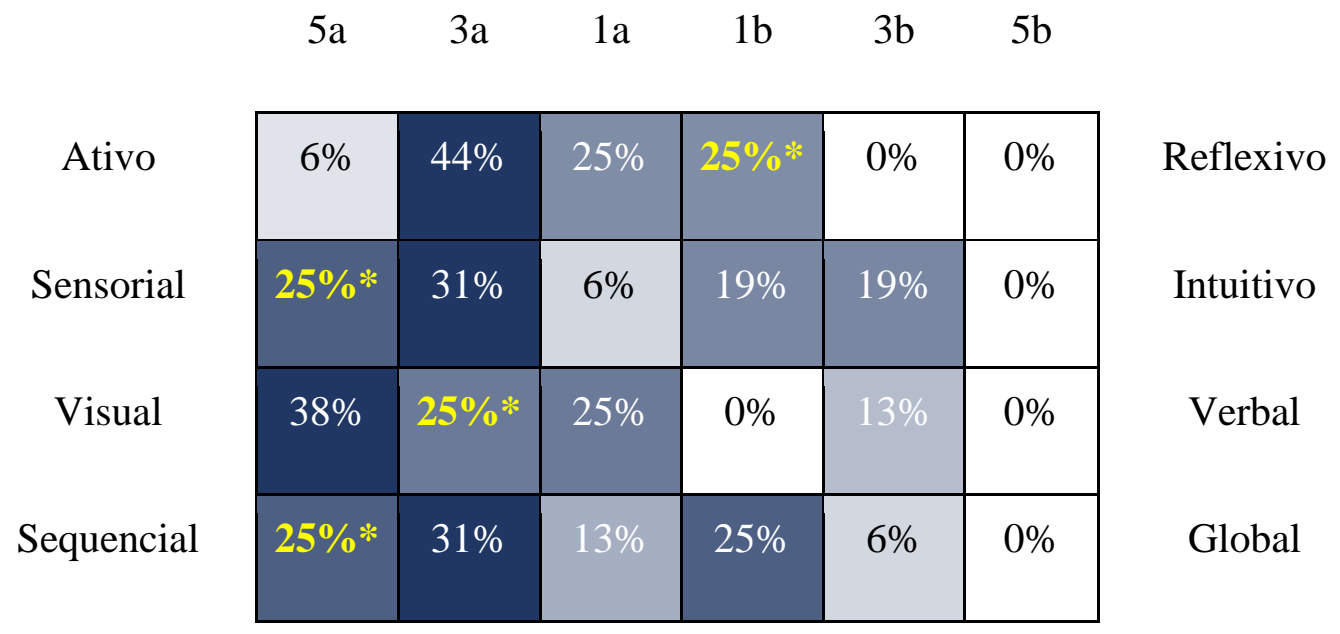

(*) Estilo do Professor de Matemática. Fonte: Próprios autores.

De forma semelhante, foi feita a análise dos estudantes com menor aprendizagem em Estabilidade das Construções (Tabela 3). O estilo predominante nesse grupo é o: ativo (1a) / sensorial (5a) / visual (3a) / sequencial (5a e 3a). O estilo do professor de Estabilidade das Construções é o: reflexivo (1b) / sensorial (3a) / visual (5a) / global (1b). De maneira semelhante ao verificado para os estudantes com as menores notas em Matemática (Tabela 1), os maiores percentuais são constatados nas mesmas regiões, isto é, para as mesmas intensidades de cada uma das quatro dimensões.

Tabela 3. Estilos de aprendizagem dos estudantes com as menores notas em Estabilidade das Construções.

\begin{tabular}{c|c|c|c|c|c|c|c|}
\multicolumn{1}{c}{$5 \mathrm{a}$} & $3 \mathrm{a}$ & $1 \mathrm{a}$ & $1 \mathrm{~b}$ & $3 \mathrm{~b}$ & $5 \mathrm{~b}$ & \\
\multirow{3}{*}{ Ativo } & $25 \%$ & $13 \%$ & $31 \%$ & & $6 \%$ & $0 \%$ & \multirow{2}{*}{ Reflexivo } \\
\cline { 2 - 7 } Sensorial & $44 \%$ & $19 \% *$ & $13 \%$ & $6 \%$ & $19 \%$ & $0 \%$ & \multirow{2}{*}{ Intuitivo } \\
\cline { 2 - 7 } Visual & $19 \% *$ & $50 \%$ & $13 \%$ & $13 \%$ & $0 \%$ & $6 \%$ & Verbal \\
\cline { 2 - 7 } Sequencial & $25 \%$ & $25 \%$ & $19 \%$ & & $13 \%$ & $0 \%$ & \multirow{2}{*}{ Global }
\end{tabular}

(*) Estilo do Professor de Estabilidade das Construções. Fonte: Próprios autores.

Por fim, a análise dos estilos dos estudantes com maior aprendizagem em Estabilidade 
das Construções está na Tabela 4. O estilo predominante nesse grupo é o: ativo (3a) / sensorial (3a) / visual (5a) / sequencial (5a) ${ }^{7}$. O estilo do professor de Estabilidade das Construções é o: reflexivo (1b) / sensorial (3a) / visual (5a) / global (1b). Comparando com as constatações para a disciplina de Matemática, nota-se que as maiores notas são verificadas para estilos predominantes semelhantes nas duas disciplinas.

Tabela 4. Estilos de aprendizagem dos estudantes com as maiores notas em Estabilidade das Construções

\begin{tabular}{|c|c|c|c|c|c|c|c|}
\hline & $5 a$ & $3 a$ & $1 \mathrm{a}$ & $1 b$ & $3 b$ & $5 b$ & \\
\hline Ativo & $0 \%$ & $44 \%$ & $19 \%$ & & $6 \%$ & $0 \%$ & Reflexivo \\
\hline Sensorial & $19 \%$ & $31 \% *$ & $6 \%$ & $25 \%$ & $19 \%$ & $0 \%$ & Intuitivo \\
\hline Visual & $44 \% *$ & $13 \%$ & $25 \%$ & $0 \%$ & $19 \%$ & $0 \%$ & Verbal \\
\hline Sequencial & $31 \%$ & $25 \%$ & $6 \%$ & $31 \% *$ & $6 \%$ & $0 \%$ & Global \\
\hline
\end{tabular}

(*) Estilo do Professor de Estabilidade das Construções. Fonte: Próprios autores.

Esses dados indicam que:

- $\quad$ Estudantes com maiores notas em Estabilidade das Construções possuem estilos próximos aos do professor. Os que possuem menores notas se afastam;

- De maneira inversa, estudantes com menores notas em Matemática possuem estilos próximos aos do professor;

- Existe uma concentração dos estudantes com notas (tanto em Matemática quanto em Estabilidade das Construções) a estilos mais próximos aos polos, enquanto os com maiores notas se distribuem mais no centro (principalmente entre $3 \mathrm{a}$ e $1 \mathrm{~b}$ ). Isso sugere que um estilo de aprendizagem mais flexível é mais determinante para o desempenho do que a aproximação com o estilo do professor.

\footnotetext{
${ }^{7} 31 \%$ desse grupo também é global (1b). Contudo, como existem mais estudantes do lado "a" do que do "b", o estilo predominante dessa dimensão é o sequencial.
} 
Em relação às metodologias didáticas, tem-se que na disciplina de Matemática, o conteúdo foi desenvolvido por meio de aulas expositivas, atividades individuais, atividades em grupo e metodologias ativas. Foi seguido o livro texto para estudo dirigido e exercícios. No Primeiro momento, após a explicação do conteúdo, a turma era orientada a resolver os problemas individualmente. O objetivo era incentivar os estudantes para que aprendessem de forma autônoma e participativa a partir de problemas e situações reais. Após um tempo, era liberado a discussão em grupos. No final de cada aula, dúvidas eram resolvidas pelo professor no quadro. Eram sugeridos também sites, aplicativos e plataformas online para o ENEM (Exame Nacional do Ensino Médio). Além disso, esporadicamente era aplicado um teste surpresa para avaliar a dedicação da turma e alertá-los (mas sem valer nota). As atividades individuais correspondiam a aproximadamente $70 \%$ da nota total e as em duplas ou grupos aproximadamente $30 \%$.

Na disciplina de Estabilidade das Construções, o conteúdo foi desenvolvido por meio de aulas também expositivas e dialogadas. O professor procurava mostrar a prática do que estavam estudando, associando com as estruturas presentes no prédio do IFMG Campus Santa Luzia, bem como as mais corriqueiras que poderiam ser vistas no dia-a-dia (as estruturas nas casas de cada um por exemplo, ou seja, onde aquela matéria será aplicada primeiro de forma global, para depois mostrar a sequência para se chegar naquele resultado). As avaliações tinham, por etapa, atividades em duplas em sala de aula (onde o professor tirava as dúvidas dos estudantes à medida que as dúvidas iam surgindo), listas de exercícios (também em dupla) para se prepararem para as provas, pelo menos uma prova individual (além da Prova Integrada) e pelo menos um trabalho em Grupo, que era mais prático (maquetes, visitas técnicas por exemplo), e que os estudantes demonstravam significativo interesse. As atividades individuais correspondiam a aproximadamente $60 \%$ da nota total e as em duplas ou grupos aproximadamente $40 \%$.

Comparando as metodologias didáticas aplicadas pelos professores, percebe-se que:

- As aulas em Matemática eram mais expositivas, enquanto que as de Estabilidade, além de expositivas, eram também dialogadas, ou seja, a todo o tempo os estudantes participavam com perguntas e/ou contribuições sobre o assunto (a participação dos estudantes pode ser devido à disciplina ser mais prática, mais visual);

- Em Matemática, as atividades em sala eram primeiramente desenvolvidas individualmente e depois em grupo. Já em Estabilidade das Construções a todo era feito em duplas pelo menos; 
- As provas eram individuais em ambas as disciplinas;

- A disciplina de Matemática teve maior porcentagem de atividades individuais e consequentemente menor porcentagem de atividades em duplas ou grupo, porém percebe-se que as notas em Matemática foram melhores que em Estabilidade das Construções. Tal fato pode ter se dado devido à característica que a disciplina de Estabilidade das Construções possui, pois além de conceitos de Matemática, engloba também conceitos de Física, outra disciplina que os estudantes geralmente apresentam dificuldades.

\section{Considerações Finais}

Comparando os estilos de aprendizagem do professor com suas metodologias de ensino, tem-se que: para o professor de Estabilidade das Construções, coincidem para os 4 casos, ou seja, é mais reflexivo, sensorial, visual e global e suas metodologias refletem isso. Já para professor de Matemática coincide em apenas 2 estilos (sensorial e sequencial) e divergem em outros 2, ou seja, mesmo sendo mais reflexivo, suas metodologias demonstramse mais ativas; e mesmo sendo mais visual, suas metodologias demonstram-se mais verbais. Tal constatação sugere que o estilo de ensino do professor (sendo um reflexo direto do seu estilo de aprendizagem) pode não corresponder exatamente na sua prática docente. Ressaltase, porém, que seria necessária uma amostragem maior para que extrair conclusões mais abrangentes.

A hipótese inicial era de que o desempenho dos estudantes estaria ligado a uma convergência de estilos de aprendizagem de estudantes e professor, de acordo com o entendimento de Felder \& Silverman (1988) e Vieira Junior (2014). Isso foi verificado na disciplina de Estabilidade das Construções. Já na disciplina Matemática, os dados indicam o oposto.

Contudo, os dados aqui analisados apontam que melhores desempenhos estiveram ligados a estudantes com estilos mais flexíveis e com maior facilidade para lidar com os polos de cada dimensão. Esse foi o ponto em comum entre as duas disciplinas, conduzidas por professores com estilos notavelmente distintos. Isso sugere que o desempenho dos estudantes está mais ligado a essa flexibilidade do que a uma convergência ao estilo do professor.

É proposto aqui que a análise dos estilos de aprendizagem se torne uma prática constante nas instituições de ensino, de modo que os docentes tenham um mapeamento prévio dos perfis de estudantes com o quais estão lidando em sala de aula. E com a ferramenta criada para este estudo, os dados podem ser extraídos com significativa facilidade, bastando 
basicamente que professores e estudantes respondam ao formulário (input). Toda a compilação dos dados e geração das tabelas gráficas resumidas (output) é feita automaticamente pela ferramenta, já considerando todos os parâmetros estabelecidos por Vieira Junior (2014).

É esperado que os resultados aqui encontrados contribuam na geração de uma conscientização dos docentes sobre a necessidade de adequações nos modos de ensinar. Não é sugerido que o professor perca todas as suas características, mas sim que permaneça aberto a adaptações para uma melhor aprendizagem dos estudantes.

Como sugestões para trabalhos futuros, é proposto que mais pesquisas semelhantes a esta sejam realizadas para verificar o nível de aderência do modelo de Vieira Junior (2014) em relação à hipótese de que os estilos estão ligados ao desempenho. Ressalta-se que Vieira Junior (2014) já deixa claro que os estilos são apenas uma variável dentro do complexo universo do ensino-aprendizagem. As pesquisas podem ser feitas tanto para disciplinas isoladas quanto em situações comparativas, como no presente trabalho.

Por fim, sugere-se também o estímulo aos estudantes para conhecerem pesquisas sobre o assunto, no sentido de favorecer uma conscientização e uma responsabilização. Afinal, o processo é de ensino-aprendizagem, algo mútuo e coparticipativo. Tanto professor quanto estudante têm sua parcela de responsabilidade.

\section{Referências}

Almeida Junior, J., et al. (2018). Identificação das possíveis causas de baixo desempenho nas disciplinas de Física em Engenharias. Revista CNEC Educação. Recuperado de http://sys.facos.edu.br/ojs/index.php/cneceducacao/article/view/276.

Amaral, M. P., \& Silveira, I. F. (2014). Estilos de aprendizagem dos alunos do último ano do curso técnico de informática do Centro Federal de Educação Tecnologia de Minas Gerais: levantamento de um perfil cognitivo dominante. Revista de Produção Discente em Educação Matemática. Recuperado de http://200.144.145.24/pdemat/article/view/21245.

Bourdieu, P. (2005). A economia das trocas simbólicas. São Paulo: Perspectiva.

Brasil (2008). Lei $\mathrm{n}^{\circ}$ 11.892, de 29 de dezembro de 2008. Institui a Rede Federal de Educação Profissional, Científica e Tecnológica, cria os Institutos Federais de Educação, 
Ciência e Tecnologia, e dá outras providências. Presidência da República. Casa Civil. Subchefia para Assuntos Jurídicos, 2008. Recuperado de http://www.planalto.gov.br/ccivil_03/_Ato2007-2010/2008/Lei/L11892.htm.

Brasil (2016). Portal da Rede Federal de Educação Profissional, Científica e Tecnológica. Recuperado de http://redefederal.mec.gov.br/historico.

Catholico, R. A. R., \& Oliveira Neto, J. D. (2009). Inventário de estilos de aprendizagem em um curso técnico de eletroeletrônica. Revista Eletrônica de Educação e Tecnologia do SENAI-SP. ISSN: 1981-8270. Recuperado de http://www.npt.com.br/wpcontent/uploads/2018/03/Inventario_senai.pdf.

Coffield, F., et al. (2004). Learning styles and pedagogy in post-16 learning: a systematic and critical review. London: Learning and Skills Research Centre.

Costa Junior, E., et al. (2017). Um estudo estatístico sobre o aproveitamento em Física de alunos de ensino médio e seus desempenhos em outras disciplinas. Revista Brasileira de Ensino de Física. doi:10.1590/1806-9126-rbef-2016-0145.

Dantas Filho, J. V. (2018). Baixo rendimento na disciplina de matemática. EDUCA - Revista Multidisciplinar em Educação, p. 98-113. 2018. ISSN 2359-2087. doi:10.26568/23592087.2017.2129.

Felder, R., \& Silverman, L. (1988). Learning and teaching styles in engineering education. Journal of Engineering Education, p. 674-681. Versão traduzida por Niltom Vieira Junior.

Felder, R., \& Soloman, B. (1991). Index of learning styles questionnaire. North Carolina State University, Raleigh. Recuperado de http://www.engr.ncsu.edu/learningstyles/ilsweb.html.

Figueiredo, R., et al. (2008). Estilos de aprendizagem no ensino técnico agropecuário das escolas técnicas federais do Estado de Goiás. Revista Brasileira de Gestão e Desenvolvimento Regional, 41-57. Recuperado de https://rbgdr.net/revista/index.php/rbgdr/article/view/134. 
G1. (2018). O Portal de notícias da Globo. 7 de cada 10 alunos do ensino médio têm nível insuficiente em português e matemática, diz MEC. Recuperado de https://g1.globo.com/educacao/noticia/2018/08/30/7-de-cada-10-alunos-do-ensino-mediotem-nivel-insuficiente-em-portugues-e-matematica-diz-mec.ghtml>.

Honigsfeld, A., \& Dunn, R. (2010). High School Male and Female Learning-Style Similarities and Differences in Diverse Nations. The Journal of Educational Research, p. 195-206. doi: 10.1080/00220670309598809.

INEP. (2003). No ensino médio, 67\% dos estudantes têm desempenho crítico em Matemática. Recuperado de http://portal.inep.gov.br/artigo/-/asset_publisher/B4AQV9zFY7Bv/content/noensino-medio-67-dos-estudantes-tem-desempenho-critico-em-matematica/21206.

Karklins, L., \& Mendoza, J. (2016). Literature Review: Architects and mental health. A report prepared for the NSW Architects Registration Board, ConNetica, Caloundra, Qld. Recuperado de http://bit.ly/2Mgneik.

Leitão, M. B. P. (2006). Estilos de aprendizagem sob a ótica da Psicologia Evolucionista. Dissertação (Mestrado em Psicobiologia). Universidade Federal do Rio Grande do Norte. Recuperado de https://repositorio.ufrn.br/jspui/handle/123456789/17379.

Luckesi, C. C. (2014). Sobre as notas escolares: distorções e possibilidades. São Paulo: Cortez.

Matthews, D., \& Hamby, J. (1995). A comparison of the learning styles of high school and college/university students. Clearing House, 257. doi: 10.1080/00098655.1995.9957245.

Moreira, M. A. (2000). Ensino de física no Brasil: retrospectiva e perspectivas. Revista Brasileira de Ensino de Física. Recuperado de http://www.sbfisica.org.br/ rbef/pdf/v22a13.pdf.

Pereira, A. S., et al. (2018). Metodologia do trabalho científico. Santa Maria: UAB / NTE / UFSM. 
Piazzi, P. (2014). Aprendendo inteligência. São Paulo: Aleph.

Saeb. (2017). Relatório Saeb 2017. Recuperado de http://portal.inep.gov.br/documents/ 186968/484421/RELAT\%C3\%93RIO+SAEB+2017/fef63936-8002-43b6-b7414ac9ff39338f?version=1.0.

Santos, F. A. C., et al. (2020). Evasão no IFMG- Campus Piumhi: Estudo de Caso no Curso Técnico Subsequente em Edificações. Revista Científica Multidisciplinar Núcleo do Conhecimento, pp. 65-78. doi: 10.32749/nucleodoconhecimento.com.br/engenhariacivil/evasao-no-ifmg.

Sato, H., \& Ramos, I. M. L. (2014). Física para Edificações: Eixo Infraestrutura. Bookman Série Tekne.

Trevelin, A. T. C. (2007). A relação professor aluno estudada sob a ótica dos estilos de aprendizagem: análise em uma Faculdade de Tecnologia - Fatec. Tese (Doutorado em Engenharia de Produção). Escola de Engenharia de São Carlos. Recuperado de https://teses.usp.br/teses/disponiveis/18/18140/tde-07052008-160809/en.php.

Vieira Junior, N. (2014). Construção e validação de um novo índice de estilos de aprendizagem. MCTI; UNESCO; CNPq. (Org.). Educação para a ciência. Brasília: MCTI.

Vieira Junior, N. (2017). Metodologias de Ensino e Aprendizagem. Apostila (Pós-Graduação em Docência) - Instituto Federal de Minas Gerais, 2018. Arcos.

\title{
Porcentagem de contribuição de cada autor no manuscrito
}

\author{
Ramon Paes Guimarães - $45 \%$ \\ Wanderson Gonçalves Machado - $45 \%$ \\ Reginaldo Gonçalves Leão Junior - 10\%
}

